\title{
A GUIDE TO THE ARRANGEMENT OF ENTRIES
}
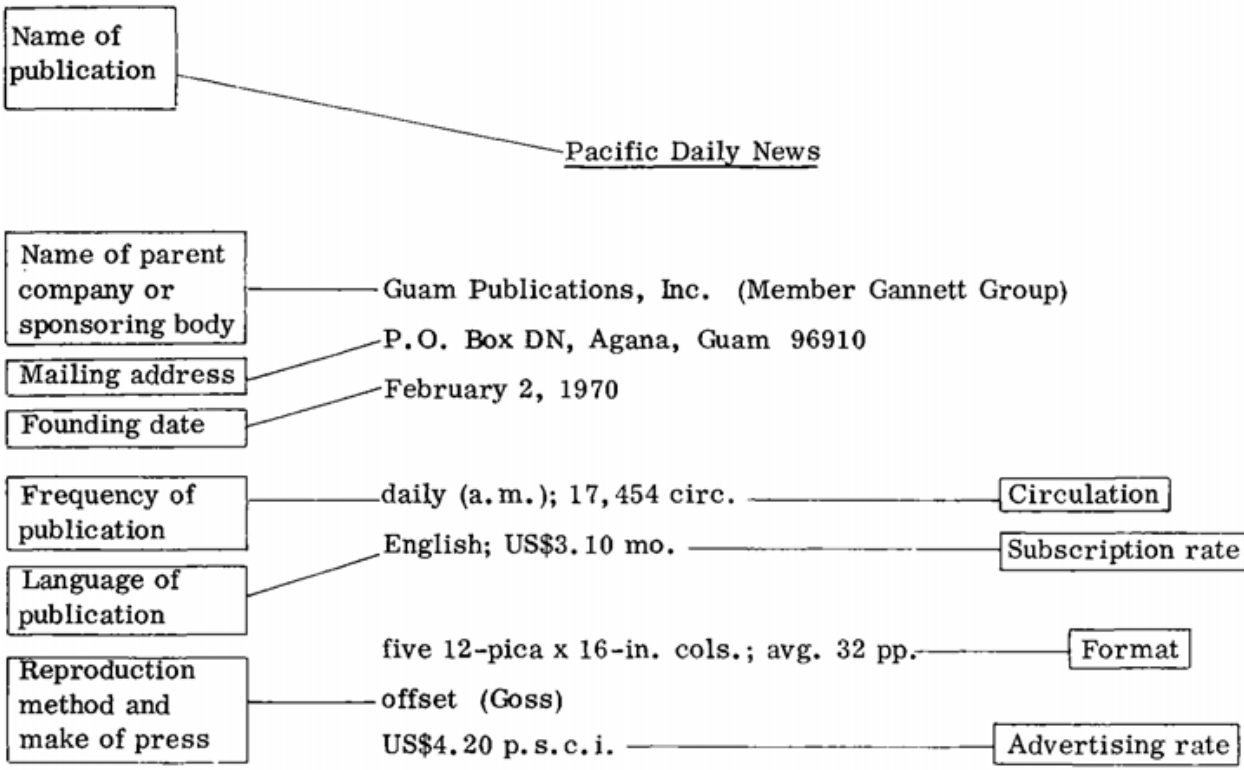

$\begin{aligned} & \text { Major sources of } \\ & \text { international and } \\ & \text { Pacific area news }\end{aligned}$
AP, UPI, N.Y. Times Service, Washington Post-
Los Angeles Times Service

Publisher: Robert E. Udick

Editor: Joseph C. Murphy

Managing Editor: John Walter

Advertising Manager: Josephine Concepcion

Business Editor: Martha Ruth

Sports Editor: Dan Gibson

Women's Editor: Linda Kauss

Reporters: Janet Go, Margery Clapp, Patsy

Harrison, Jake Skjvaril

Special Writers: Mike Malone, Trust Territory of the Pacific Islands 